\title{
A Development-Based Approach to Global Climate Policy
}

\author{
Susan G. Spierre Arizona State University, susan.spierre@asu.edu \\ Thomas P. Seager Arizona State University, thomas.seager@asu.edu \\ Evan Selinger Rochester Institute of Technology, evan.selinger@rit.edu
}

\begin{abstract}
Under current technology constraints, $\mathrm{CO}_{2}$ emissions are a pre-requisite to achievement of high levels of well-being in all countries. However, past a point of diminishing returns, additional $\mathrm{CO}_{2}$ does not improve measures of educational attainment, wealth, or life expectancy. While some climate change mitigation policies advocate a permit-trading scheme that would allow wealthy countries to purchase the right to $\mathrm{CO}_{2}$ emissions from poor countries, this paper questions whether equitable human development outcomes will result.
\end{abstract}

Introduction. The relationship between economic growth (e.g., in terms of gross domestic product or gross national income) and carbon dioxide (CO2) is understood to be more or less a direct relationship (Figure 1). As pointed out in Sunita Narain (2013), director of India's Society for Environmental Communications, no country has de-linked economic growth from $\mathrm{CO}_{2}$ emissions. These interdependencies are problematic for developing nations in particular, given that efforts to stabilize the climate system will undoubtedly place limits on $\mathrm{CO}_{2}$ emissions, a byproduct of energy production under current technology constraints, but also a major GHG contributing to global warming.

When climate change is defined as an economic problem, the solution is also economic. The common economic approaches appeal to issues of economic efficiency, for instance focusing on GDP losses as a result of a warmer world (e.g., Tol, 2009; Stern, 2007; Nordhaus, 2007). When social impacts are considered in economic analysis, they are integrated by placing an estimated monetary value on non-market goods (e.g., human health impacts) so that they may be internalized by the market. Consequently, climate policy designed to reduce GHG mitigation costs is accomplished via a market-based, cap and trade system, where a limit is placed on the overall amount of emissions allowed globally, emission allowances are allocated to polluting parties, and those polluting more than their allowed amount can buy additional allowances from others producing less. This enables an economically efficient allocation of emissions, since parties that can make significant reductions inexpensively will, and those that find reductions too expensive will instead pay for their right to emit.

Proceedings of the International Symposium on Sustainable Systems and Technologies (ISSN 2329-9169) is published annually by the Sustainable Conoscente Network. Melissa Bilec and Jun-ki Choi, co-editors. ISSSTNetwork@gmail.com.

Copyright ( 2013 by Susan Spierre, Thomas P. Seager and Evan Selinger. Licensed under CC-BY 3.0.

Cite as:

A Development-Based Approach to Global Climate Policy. Proc. ISSST, Susan Spierre, Thomas P. Seager, Evan Selinger. http://dx.doi.org/10.6084/m9.figshare.805097. v1 (2013) 
On the other hand, recent development and policy studies look more broadly at the relationship between $\mathrm{CO}_{2}$ and human development. At the international level, human development is typically measured using the United Nations Human Development Index (HDI) which encompasses both economic and social dimensions of development. Specifically, the HDI normalized and aggregates data of a country's gross national income, average life expectancy, and years of schooling ( all weighted equally) into a single value on a scale from zero to one. The HDI therefore considers more than the distribution of resources, but it also captures some of the common end-states of development progress that resources, like income, can enable. These aspects are important to consider in the context of climate change policy because $\mathrm{CO}_{2}$ restrictions, which constrains fossil-fuel energy production, may inhibit the ability of underdeveloped nations to provide essential energy services to citizens. Even today, 1.6 billion people (almost a third of humanity) have no electricity, and up to a billion more only have access to unreliable electricity networks, and consequently lack essential energy services for schools, health centers and income generation (Birol, 2007). The HDI is therefore an improved measure of development, relative to economic estimates, for studying the impacts of climate policy on international socio-economic development progress. From this perspective, the usual market-based approach to emission allocation might not be appropriate, considering the value HDI places on intrinsic social well-being.

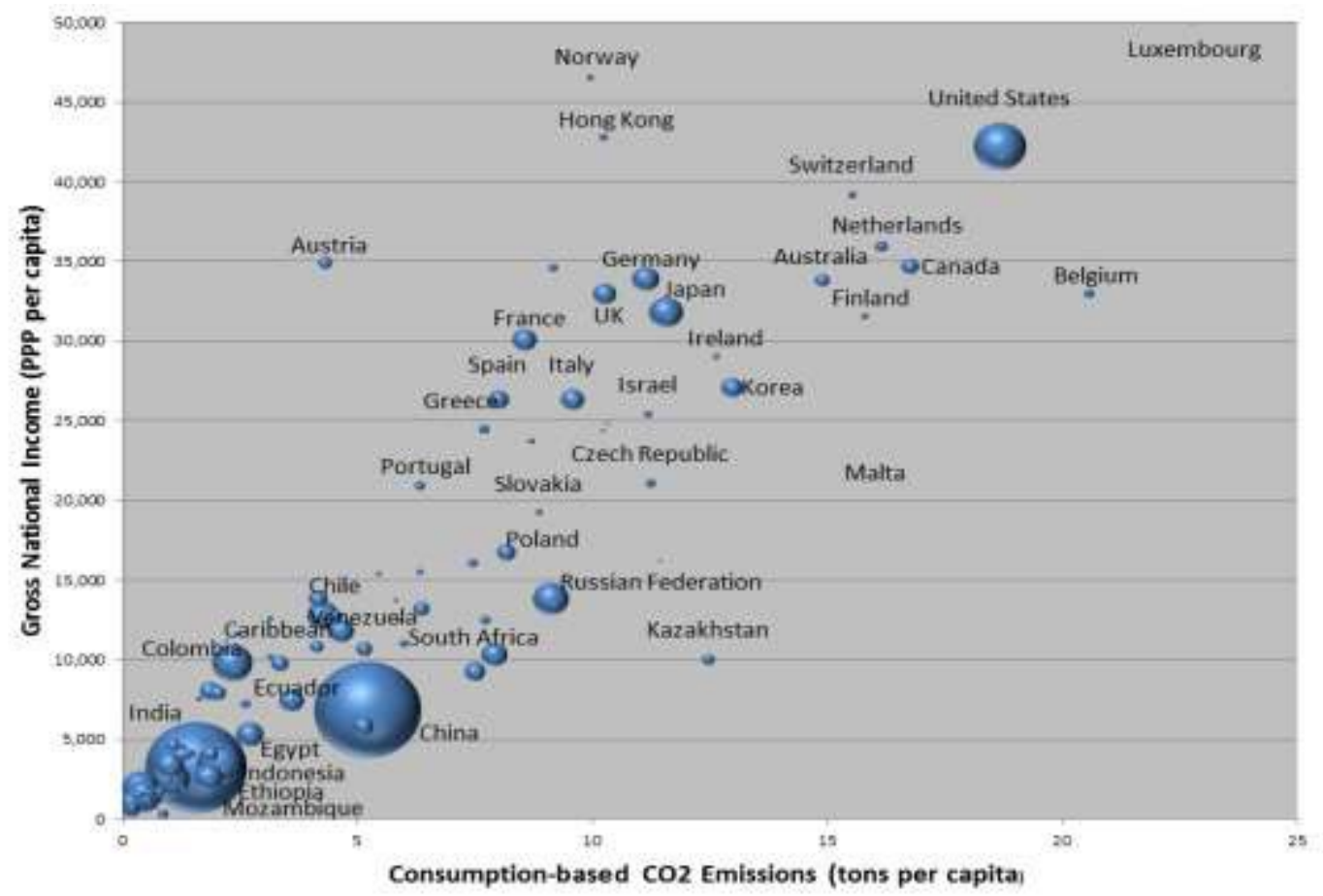

Figure 1. Comparison between consumption-based $\mathrm{CO}_{2}$ emissions (where the emission generated in the production of goods and services get allocated to the consuming nation) and gross national income (GNI) for many nations. $\mathrm{CO}_{2}$ emission data provided Peters et al. (2011), GNI data downloaded from the UNDP. 
Measuring development with the HDI changes the linear-type relationship observed in Figure 1 to a diminishing-returns relationship shown in Figure 2. Simply put, energy consumption and its resulting emissions are highly correlated with achieved $\mathrm{HDI}$, as it is with economic development, but the latter is distinct because it indicates that as nations increase their per capita $\mathrm{CO}_{2}$ emissions, those emissions are resulting in less and less HDI improvements. This indicates that underdeveloped nations are more efficient with their $\mathrm{CO}_{2}$ emissions in terms of improving HDI.

Subsequently, economic losses from GHG mitigation in developed nations may not be as critical to human development progress as an economic analysis would predict, which questions the viability of economic driven mechanisms to effectively address current human development inequities around the world. This research builds on previous empirical work to critically examine policy prescriptions focused on market-based methods for emission allocation in their ability to address human development inequities. To conclude, we offer a novel climate policy proposal aimed at preventing unintended human development consequences of an unlimited market of $\mathrm{CO}_{2}$ permits.

Empirical Evidence. Previous empirical work has begun to clarify the relationship between $\mathrm{CO}_{2}$ and $\mathrm{HDI}$. As mentioned prior, many studies recognize that per capita $\mathrm{CO}_{2}$ emissions and HDI level of nations are highly correlated (Alam et al.,1991; Alam, et al.,1995; Pasternak, 2000; Goldenberg et al., 2004; Dias et al.,2006; Moran et al., 2010). Studies also recognize the diminishing returns to $\mathrm{HDI}$ as nations transition to higher levels of per capita emissions (Pasternak, 2000; Martinez and Ebenhack, 2008; Mechtenberg; Spierre et al., 2013). A sensitivity analysis on the $2010 \mathrm{HDI}$ methodology shows that the diminishing returns to HDI from $\mathrm{CO}_{2}$ are inherent to specific development indicators (i.e., life expectancy and years of schooling) and not driven by the functional form of the HDI (Spierre et al.,2013). In terms of more specific development indicators, a recent study found that high life expectancy can be achieved at a large range of carbon emission levels, whereas income is much more closely linked with carbon (Steinberger, et al., 2012). A few studies have also looked at the comparison of $\mathrm{CO}_{2}$ emissions and HDI over time. Steinberger \& Roberts (2010) found that HDI levels were achieved at decreasing levels of energy and carbon emissions among many nations from 1975 to 2005, suggesting a decoupling of energy and carbon. This finding is supported when individual development pathways are examined, since the saturation-like trend is not consistently detected, especially among highly developed nations (Steinberger et al., 2012; Spierre et al., 2013). This suggests that no generalizable model of development exists for all nations. Nevertheless, consistent advances in HDI are found among many of the least developed nations (HDI below 0.5) as emissions increase over time (Spierre et al., 2013).

Elsewhere, we have also studied the $\mathrm{CO}_{2}$ trade characteristics of underdeveloped nations from 1990 to 2010. We found that many of the underdeveloped countries (with an HDI below 0.8 in 2010) that experienced the greatest gains in HDI from 1990 to 2010 are also nations that have, or are in the process of moving toward, outward oriented trade policies that involve increased domestic capabilities for product manufacture and export. This indicates that the ability to emit $\mathrm{CO}_{2}$ is at least a co-requisite in the export oriented development strategies of nations that attained the greatest HDI improvements (Spierre et al., 2013). 


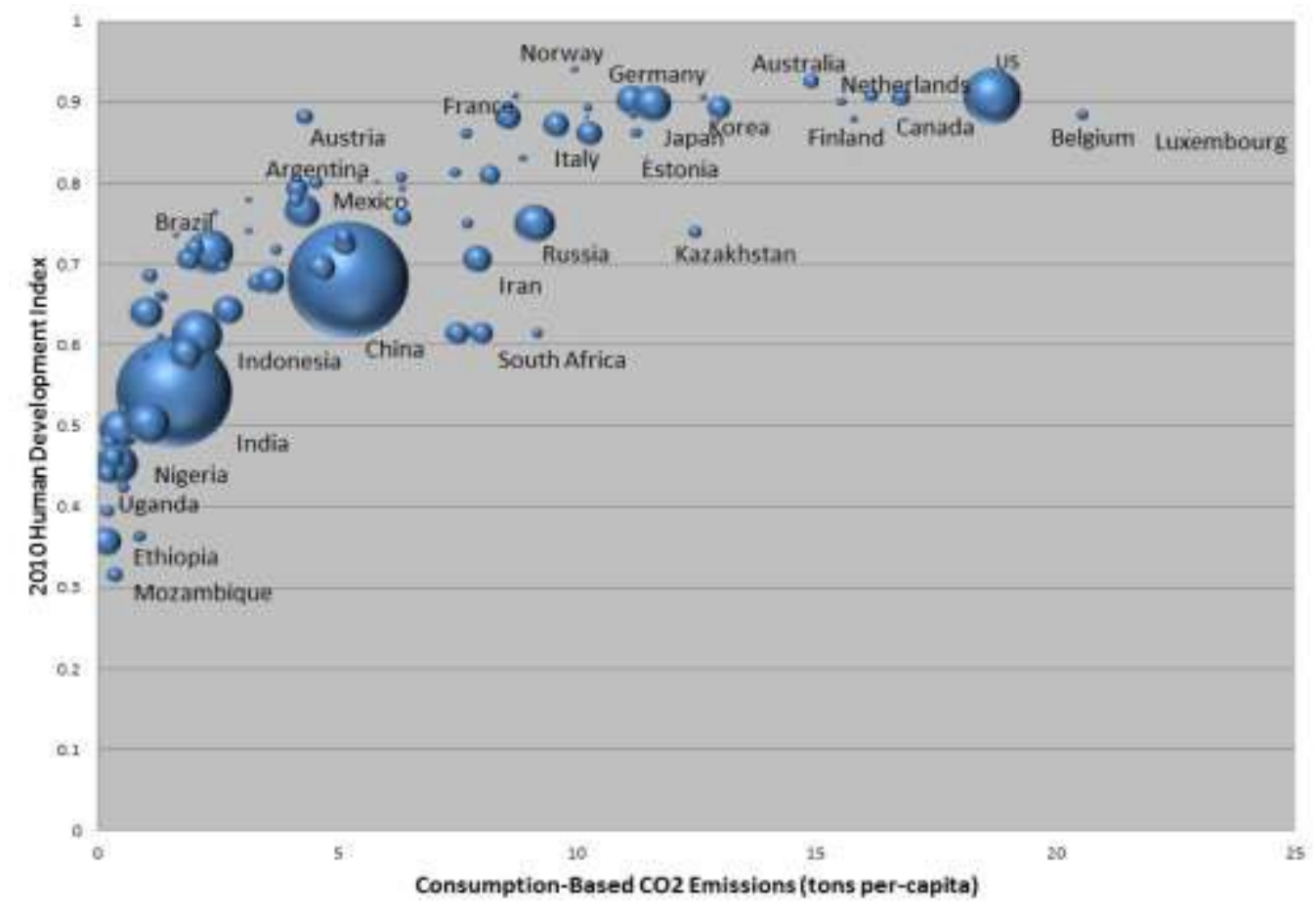

Figure 2. Comparison between consumption-based $\mathrm{CO}_{2}$ emissions (where the emission generated in the production of goods and services get allocated to the consuming nation) and Human Development Index (HDI) levels for many countries in 2010. $\mathrm{CO}_{2}$ data retrieved from Peters et al. (2011) and HDI levels are from the UNDP.

A Theoretical Framework. To help understand the empirical relationship between $\mathrm{CO}_{2}$ and HDI we employ the capabilities approach (CA) which is also the theoretical basis of the HDI. The CA is a theory of basic human entitlements that provides a standard for determining whether people possess the various capabilities necessary for living a genuinely human life (Sen 1999a, 1999b; Nussbaum and Sen, 1992; Nussbaum 2000, 2006). It also provides a framework for thinking about development in terms beyond those used in traditional welfare economics, where the focus is not only on the distribution of resources but also on what they enable people to do. For example, Sen (1990) observes that societies typically differ in their capacity to convert income and commodities into valuable human achievements. A list of ten suggested human entitlements that societies should provide their citizens are provided by Nussbaum (1997) and is listed in Figure 3.Figure 3 also shows examples of mechanisms needed to transform income, commodities, and rights into actual achievements, such as communication, transportation, education, and health care. From a capabilities perspective, energy and $\mathrm{CO}_{2}$ are co-requisite for transforming resources into achieved human development because they enable modern forms of communication, transportation, education, and health care, among others. As Ezor (2009) points out, "Electricity serves as a catalyst, making other pillars of development-education, modern healthcare, income generating activities, etc."

This framework helps to explain our empirical evidence. According to our theory, the emissions generated to build basic infrastructure (such as roads, communication, and energy systems) and provide essential services (e.g., hospitals, schools, banks) directly work to improve human development, which would explain why $\mathrm{CO}_{2}$ and $\mathrm{HDI}$ remain highly correlated within the least developed nations of the world. At the same time, this framework elucidates the notion that 
income and resources do not always lead to human development improvements if a society lacks the capacity to transform them into valuable achievements. Additionally, in the case of wealthy nations, income can be used to purchase luxury goods and services that do not lead to improvements in human development indicators. This latter concept explains the diminishing returns to $\mathrm{HDI}$ from per capita $\mathrm{CO}_{2}$ emissions found in empirical studies. Next, we use this established $\mathrm{CO}_{2}$-development framework as a basis to critique popular market-based policy prescriptions.

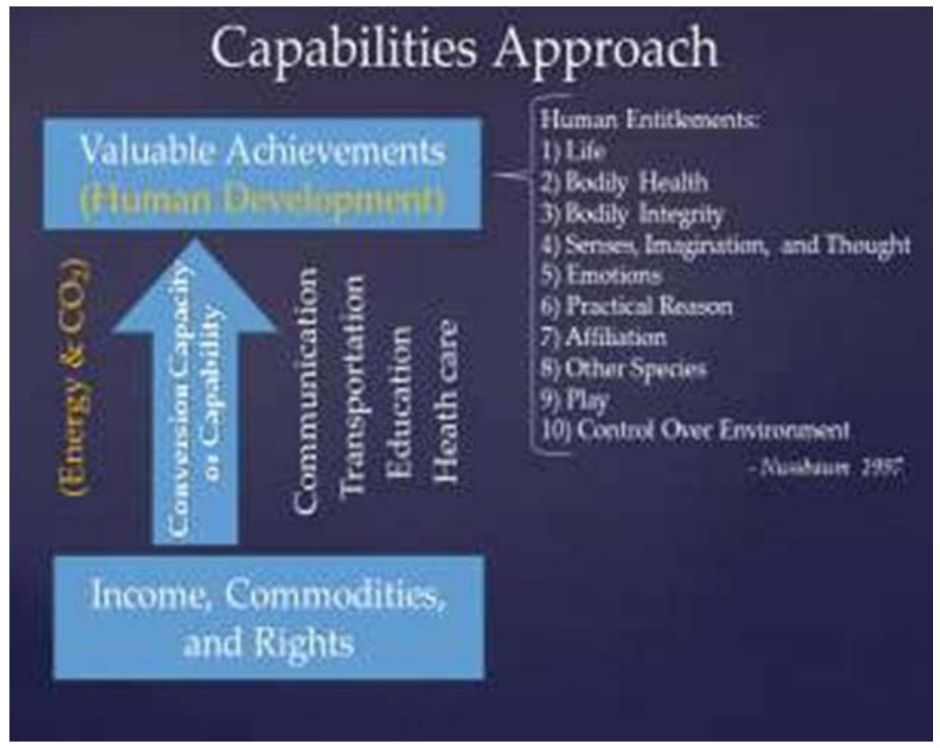

Figure 3. Conceptual Framework of the Capabilities Approach applied to the $\mathrm{CO}_{2}-$ Development Relationship.

A Critical Assessment of an Unlimited CO2 Market. From a human development perspective, market-based policy that result in the trade of money for emission rights undermine considerations of human development equity when applied to countries of different development levels. Standard neo-classical economic models are based on the assumption that individuals act rationally-i.e., that they want more rather than less of a good, and they choose options that are likely to yield the greatest satisfaction or utility for themselves. From this view, energy is a mechanism that enables the production of consumer goods and services that will most efficiently maximize global consumption (which according to neoclassical economic theory increases total utility) while complying with the global carbon cap. Yet, both the provided empirical evidence and our theoretical framework suggest that income and commodities may not be sufficient for achieving human development improvement, especially among nations with low HDI that lack the capabilities necessary to transform commodities into achieved human development.

As such, implementing a $\mathrm{CO}_{2}$ permit market globally will not necessarily foster human development, and may create additional impediments for underdeveloped nations. That is, countries that sell emission rights, because they are relatively less-efficient at production (or don't participate in production), will have to purchase many of their manufactured products from the more developed nations that bought the emission rights in the first place. This is a 'win-win' scenario for industrialized nations because they do not only have the ability to emit more than their share (they just have to pay for additional rights), but they will also generate profit from the 
sale of the manufactured goods. Also, underdeveloped nations are unlikely to invest the proceeds of emissions permit sales in effective local human development when they can gain greater risk-adjusted returns in more technologically sophisticated countries. As a result, revenues from permit sales will necessarily be directed towards increasing consumption of goods (and services) that are cost-effective to import, but less likely to result in human development improvements.

Now, let us extend the capability approach to assess the practicality of improving development through an emissions market using the example of water, an essential resource in a country's development and to an individual's well-being. Historically in developed countries, the establishment of a distribution system to disseminate potable water has proven critical for public health improvements (Nelson, 2001). However, for underdeveloped countries, access to treated water supplies is poor. The World Health Organization (WHO) and UNICEF (2000) estimate that, in the largest cities, those with a household or yard connection range from only $43 \%$ in Africa, to $77 \%$ in Asia, Latin America and the Caribbean. Moreover, the treatment and distribution of water is expensive, energy intensive, and by necessity a local process (Mintz et al., 2001). If the ability of a developed country to pay for $\mathrm{CO}_{2}$ emissions exceeds that of the local populace in an underdeveloped country, then it is in the best short-term interest for the underdeveloped country to sell their extra emissions rights to the developed nation. However, there can be nothing gained from this transaction in terms of creating a long-term, sustainable water supply.

In other words, the income gained from permit sales will not increase the developing country's capability to provide potable water to its citizens. Drawing upon this example and others (e.g., health care services and education), we reason that unlimited emissions trading is an insufficient mechanism for enhancing the capabilities of people living in developing countries. As Sachs et al. (2004) explains, escaping the poverty trap and establishing self-sustained growth in Sub-Sahara Africa will require outside help in building their domestic capabilities (such as infrastructure, institutions and human capital) through increased ODA and trade reforms appropriate for the region before they can benefit from market-based sustained growth.

Yet, unlimited emission markets allocate $\mathrm{CO}_{2}$, a mechanism of converting resources into human development, to the most efficient producers rather than those most in need from a development perspective. This is especially troubling given that post-Kyoto policy discussions indicate a transition toward an emissions trading scheme between big emitters at all development levels.

\section{Policy Proposal}

Considering existing empirical evidence, the established theoretical framework, as well as the arguments against unlimited $\mathrm{CO}_{2}$ permit markets, we are able to highlight three components of future international climate policy that will least-likely impact international human development progress, including 1) placing the greatest restrictions on the most developed nations, whose human development is least likely to be impacted, 2) restriction placed on underdeveloped nations should be based on future human development need, since $\mathrm{CO}_{2}$ is at least a corequisite for achieving human development, and 3) emissions trading should be prohibited between countries of different development levels. The latter may be achieved by limiting emissions trading to nations with similar human development levels. Although less economically efficient, our analysis indicates that the limit on trade is more developmentally efficient, since it will result in greater improvements in the human condition, especially in underdeveloped nations. In prohibiting emissions sales between countries of different development stages, we 
prevent placing underdeveloped nations in a position where they choose between short-term poverty alleviation and sustainable development over the long term.

Our approach incorporates the appeal of placing primary responsibility of reducing emissions on developed countries, and therefore internalizes the external costs of greenhouse gas emissions, but also focuses on the importance of improved development in countries that are still developing. Specifically, it stresses that growth in poor countries is still essential, and rich countries that are already sufficiently developed will no longer be improved by quantitative growth, but rather by more qualitative growth (e.g., through increased social capital). It is the more qualitative growth among nations that will enable reductions in $\mathrm{CO}_{2}$ emissions, as the focus of development shifts away from consumption.

\section{References}

Alam, M.S., Bala, B.K., Huq, A.M.Z., Matin, M.A. (1991). A model for the quality-of-life as a function of electrical energy-consumption. Energy 16 (4), 739-745.

Alam, M.S., Roychowdhury, A., Islam, K.K., Huq, A.M.Z. (1998). A revisited model for the physical quality of life (PQL) as a function of electrical energy consumption. Energy 23 (9), 791-801.

Birol, F. (2007). Energy Economics: A Place for Energy Poverty in the Agenda. The Energy Journal, 28(3), 1-6. http://dx.doi.org/10.5547/ISSN0195-6574-EJ-Vol28-No3-1

Clark (Spierre), S. (in press). Examining a Sustainable Approach to Global Climate Policy. (Dissertation). Arizona State University

Dias, R.A., Mattos, C.R., Balestieri, J.A.P., 2006. The limits of human development and the use of energy and natural resources. Energy Policy 34 (9), 1026-1031.

Ezor, Z. (2009) Power to the People: Rural Electrification in Uganda. Available at: http://digitalcollections.sit.edu

Goldenberg, J., La Rovere, E.L., Coelho, S.T. (2004). Expanding access to electricity in Brazil. Energy for Sustainable Development, 8(4), 86-94.

Martínez, D. M. \& Ebenhack, B.W. (2008). Understanding the role of energy consumption in human development through the use of saturation phenomena. Energy Policy, 36,14301435. http://dx.doi.org/10.1016/j.enpol.2007.12.016

Mechtenberg, A., Borchers, K. Miyingo, E.W., Hormasji, F., Hariharan, A., Makanda, J.V., Musaazi, M.K. (2012). Human power (HP) as a viable electricity portfolio option below 20 W/Capita. Energy for Sustainable Development, 16, 125-145. http://dx.doi.org/10.1016/j.esd.2011.12.006

Mintz, E., Bartram, J., Lochery, P., Wegelin, M. (2001) "Not Just a Drop in the Bucket: Expanding Access to Point-of-Use Water Treatment Systems" American Journal of Public Health, 91, 10. pp. 1565-1570

Moran, D.D., Wackernagel, M., Kitzes, J.A., Goldfinger, S.H., \& Boutaud, A. (2008). Measuring sustainable development - nation by nation. Ecological Economics, 64 (3), 470-474. http://dx.doi.org/10.1016/j.ecolecon.2007.08.017

Narain, Sunita. "Environmentalism of the Poor vs. Environmentalism of the Rich". Wrigley Lecture Series. School of Sustainability, Arizona State University, Tempe, AZ, March 27, 2013.

Nelson, K. (2001) "Early history of infectious disease: epidemiology and control of infectious diseases" in Infectious Disease Epidemiology: Theory and Practice K. E. (Nelson, C. Masters Williams \& Graham N. M. H. eds). Aspen Publishers, Gaithersburg, Maryland.

Nordhaus, W.D. (2007). The challenge of global warming: economic models and environmental 
policy, July 24, 2007, Yale. Available at:

http://nordhaus.econ.yale.edu/dice mss 072407 all.pdf

Nussbaum, M. (2000) Women and Human Development: The Capabilities Approach, Cambridge University Press, Cambridge MA.

Nussbaum, M. (1997). Capabilities and Human Rights. Fordham Law Review, 273.

Nussbaum, M. (2006) Frontiers of Justice: Disability, Nationality, Species Membership, Harvard University Press, Cambridge MA.

Nussbaum, M., Sen, A. (1992) The Quality of Life, Oxford University Press, Oxford.

Pasternak, A.D., (2000). Global Energy Futures and Human Development: a framework for analysis. US Department of Energy, Oak Ridge.

Pasternak, A.D., (2000). Global Energy Futures and Human Development: a framework for analysis. US Department of Energy, Oak Ridge.

Peters, G., Minx, J., Christopher, J., Weberd, L. and Edenhoferc, O. (2011) "Growth in emission transfers via international trade from 1990 to 2008" PNAS, 108, 21. pp. 8903-8908.

Rogelj J, Nabel J, Chen C, Hare W, Markmann K, et al. (2010) Copenhagen accord pledges are paltry. Nature 464: 1126-1128.

Sachs, J. McArthur, J.W., Schmidt-Traub, G. Kruk, M., Bahadur, C., Faye, M., and McCord, G. (2004). Ending Africa's Poverty Trap. Economic Studies Program, The Brookings Institution, vol. 35(1), pages 117-240.

Sandel, M.J. (2012). What Money Can't Buy: The Moral Limits of Markets. New York: Farrar, Strauss and Giroux.

Sen, A. (1999a) Commodities and Capabilities, Oxford University Press, Oxford. Sen, A. (1999b) Development as Freedom, Anchor Books, New York.

Sen, A. K. (1990). Development as Capability Expansion, in Keith Griffin and John Knight (eds), Human Development and the International Development Strategy for the 1990s, London: Macmillan,41-58.

Spierre,S.G., Seager, T.P., Selinger, E. (2013). The Diminishing Returns to the 2010 Human Development Index. Sustainable Development (in press).

Steinberger, J. \& Roberts T. (2010). From constraint to sufficiency: The decoupling of energy and carbon from human needs, 1975-2005. Ecological Economics, 425-433.

http://dx.doi.org/10.1016/j.ecolecon.2010.09.014

Steinberger, J., Roberts, T. Peters, G. \& Baiocchi, G. (2012). Pathways of human development and carbon emissions embodied in trade. Nature Climate Change. http://dx.doi.org/10.1038/nclimate1371

Stern, N. (2007). The Economics of Climate Change: the Stern Review. Cambridge: Cambridge University Press.

Tol R (2009) The Economic Effects of Climate Change. Journal of Economic Perspectives, 23 (2): 29-51.

World Health Organization, United Nations Children's Fund (2000), Water Supply and Sanitation Council. Global Water Supply and Sanitation Assessment 2000 Report. New York, NY:UNICEF; 2000 